\title{
Monte Carlo Evaluation of Auger Electron-Emitting Theranostic Radionuclides
}

\author{
Nadia Falzone ${ }^{1,2}$, José M. Fernández-Varea ${ }^{3}$, Glenn Flux ${ }^{4}$, and Katherine A. Vallis ${ }^{1}$ \\ ${ }^{I}$ Department of Oncology, CR-UK/MRC Oxford Institute for Radiation Oncology, University of Oxford, Oxford, United Kingdom; \\ ${ }^{2}$ Department of Biomedical Science, Tshwane University of Technology, Pretoria, South Africa; ${ }^{3}$ Facultat de Fisica (ECM and ICC), \\ Universitat de Barcelona, Barcelona, Spain; and ${ }^{4}$ Physics Department, Royal Marsden NHSFT, Sutton, Surrey, United Kingdom
}

Several radionuclides used in medical imaging emit Auger electrons, which, depending on the targeting strategy, either may be exploited for therapeutic purposes or may contribute to an unintentional mean absorbed dose burden. In this study, the virtues of 12 Auger electron-emitting radionuclides were evaluated in terms of cellular $S$ values in concentric and eccentric cell-nucleus arrangements and by comparing their dose-point kernels. Methods: The Monte Carlo code PENELOPE was used to transport the full particulate

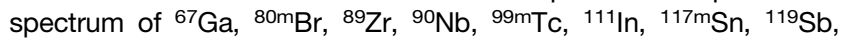
123।, ${ }^{125}$, ${ }^{195 m P t}$, and ${ }^{201} \mathrm{TI}$ by means of event-by-event simulations. Cellular $S$ values were calculated for varying cell and nucleus radii, and the effects of cell eccentricity on $S$ values were evaluated. Dosepoint kernels were determined up to $30 \mu \mathrm{m}$. Energy deposition at DNA scales was also compared with an a emitter, ${ }^{223}$ Ra. Results: PENELOPE-determined $S$ values were generally within $10 \%$ of MIRD values when the source and target regions strongly overlapped, that is, $S$ (nucleus $\leftarrow$ nucleus) configurations, but greater differences were noted for $S$ (nucleus $\leftarrow$ cytoplasm) and $S$ (nucleus $\leftarrow$ cell surface) configurations. Cell eccentricity had the greatest effect when the nucleus was small, compared with the cell size, and when the radiation sources were on the cell surface. Dose-point kernels taken together with the energy spectra of the radionuclides can account for some of the differences in energy deposition patterns between the radionuclides. The energy deposition of most Auger electron emitters at DNA scales of $2 \mathrm{~nm}$ or less exceeded that of a monoenergetic 5.77-MeV a particle, but not for ${ }^{223} \mathrm{Ra}$. Conclusion: A single-cell dosimetric approach is required to evaluate the efficacy of individual radionuclides for theranostic purposes, taking cell geometry into account, with internalizing and noninternalizing targeting strategies.

Key Words: Auger electron emitters; cellular dosimetry; targeted radiotherapy; theranostics; Monte Carlo simulation; $S$ values; dose point kernels

J Nucl Med 2015; 56:1441-1446

DOI: $10.2967 /$ jnumed.114.153502

$\mathbf{T}$ he therapeutic rationale for molecularly targeted radiotherapy is the selective delivery of a radionuclide to tumor cells via

Received Dec. 23, 2014; revision accepted Jul. 8, 2015.

For correspondence or reprints contact: Nadia Falzone, Department of Oncology, CR-UK/MRC Oxford Institute for Radiation Oncology, University of Oxford, Old Road Campus Research Building, Off Roosevelt Dr., Oxford OX3 7LJ, U.K.

E-mail: nadia.falzone@oncology.ox.ac.uk

Published online Jul. 23, 2015.

COPYRIGHT (c) 2015 by the Society of Nuclear Medicine and Molecular Imaging, Inc. a targeting moiety, thereby enhancing the therapeutic index of the agent. Several Auger electron-emitting radionuclides have been proposed for molecularly targeted radiotherapy of small metastases and disseminated cancer cells, with some promising clinical results (1-3). These radionuclides are well suited to serving as molecularly targeted radiotherapy agents because of the extremely short range in matter (nanometers to a few micrometers) of the low-energy, intermediate-linear-energy-transfer (LET) Auger and Coster-Kronig electrons they emit (4). These electrons account for high energy deposition in the immediate vicinity of the decay site, and because of their short range, irradiation of normal neighboring cells is limited, thus reducing nonspecific radiotoxicity. In addition, radiation emitted during the nuclear decay can be exploited for imaging purposes either with SPECT (in the case of $\gamma$ rays in the energy range of $70-360 \mathrm{keV}$ or Bremsstrahlung imaging for pure $\beta^{-}$emitters) or PET (in the case of annihilation photons), thus making Auger electron-emitting radionuclides ideal as theranostic agents $(5,6)$.

When evaluating Auger electron-emitting radionuclides as potential theranostic agents, one should address the following aspects. The therapeutic efficacy of a radionuclide depends on the total number of electrons emitted per decay (including Auger electrons, Coster-Kronig electrons, and internal conversion electrons, as well as $\beta$ particles), along with the total energy released. When the total energy released is carried by a small number of relatively highenergy long-range electrons, then targeting of the nucleus from the cytoplasm or cell surface is possible (7). Another key factor is the physical half-life. Because the maximum theoretic specific activity of a radionuclide is inversely proportional to physical halflife, a prolonged physical half-life may result in redistribution of the therapeutic agent before sufficient decays have occurred to cause lethal damage. It is also important to consider the ratio of penetrating ( $\mathrm{x}$ rays and $\gamma$ rays) to nonpenetrating (electrons or $\beta$ particles; i.e., p/e) forms of ionizing radiation because the moderate-to-highenergy but low-LET $\gamma$ emissions from some radionuclides may irradiate and potentially kill nontargeted normal cells. It has therefore been proposed that an ideal therapeutic radionuclide should have a p.e. ratio of $2(8)$. Conversely, for imaging purposes a high proportion of $\gamma$ emissions is required, which poses a tradeoff between sparing healthy tissue surrounding the target region and providing an adequate mean absorbed dose to the target region.

The most critical point to consider in the use of Auger electronemitting radionuclides for molecularly targeted radiotherapy is the short range of Auger and Coster-Kronig electrons, as this necessitates intranuclear accumulation if therapeutic effect is to be maximized. Since the dimensions of the different DNA condensation states (e.g., chromatin fibers, nucleosomes, and double-stranded 
DNA) are within the range of typical Auger and Coster-Kronig electrons, nuclear incorporation leads to extreme radiotoxicity, resembling high-LET radiation with a relative biological effectiveness similar to that achieved by $\alpha$-emitting radionuclides (9). Several strategies have been proposed to optimally localize the radionuclides with respect to the sensitive targets in cells $(5,10,11)$. However, recent observations suggest that nuclear accumulation may not be required in order for an Auger electron-emitter to produce the highLET type of radiotoxicity (12). In contrast, radionuclides bound outside the cell nucleus (e.g., in the cytoplasm), on the cellular membrane, or extracellularly do not produce severe lethal effects and have a relative biological effectiveness comparable to that observed for low-LET radiation (13).

Regardless of the targeting strategy adopted, cellular geometry can influence the mean absorbed dose to the nucleus and thus the biological effect of an Auger electron-emitting theranostic agent. The $S$ value estimates provided by the MIRD Committee (14) assume a spheric cell geometry, but it is conceded that cellular geometry may affect these values. This was demonstrated by Nettleton et al. (15), who noted differences between $S$ value calculations in spheric and ellipsoid cell geometries, especially toward the edge of the cell. Considering that many cells exhibit irregular geometries and eccentric cell-nucleus arrangements, the dose to the nucleus may be over- or underestimated when MIRD-tabulated $S$ values are used.

The aim of this study was to evaluate the properties of 12 Auger electron-emitting radionuclides that have been proposed as theranostic agents, namely ${ }^{67} \mathrm{Ga},{ }^{80 \mathrm{~m}} \mathrm{Br},{ }^{89} \mathrm{Zr}^{1},{ }^{90} \mathrm{Nb}^{1},{ }^{99 \mathrm{~m}} \mathrm{Tc},{ }^{111} \mathrm{In}$, ${ }^{117 \mathrm{~m} S n},{ }^{119} \mathrm{Sb}^{1},{ }^{123} \mathrm{I},{ }^{125} \mathrm{I},{ }^{195 \mathrm{~m} P t}$, and ${ }^{201} \mathrm{Tl}$ (Supplemental Table 1; supplemental materials are available at http://jnm.snmjournals. org) $(16-18) .\left({ }^{89} \mathrm{Zr},{ }^{90} \mathrm{Nb}\right.$, and ${ }^{119} \mathrm{Sb}$ are not included in the MIRD monograph (19).)

For these radionuclides, we evaluated $S$ values from Monte Carlo simulations, the effect of cellular geometry and eccentric cell or nucleus arrangements on $S$ values, dose-point kernels (DPKs), and energy deposition on a DNA scale in comparison with an $\alpha$ emitter, ${ }^{223}$ Ra.

\section{MATERIALS AND METHODS}

\section{Monte Carlo Simulations: The PENELOPE Code}

The $S$ values and DPKs were calculated with the general-purpose Monte Carlo code PENELOPE (20). PENELOPE simulates the coupled electron-photon transport in arbitrary materials from $50 \mathrm{eV}$ to 1 $\mathrm{GeV}$. The simulation is controlled by 7 user-defined parameters: Eabs (1), Eabs(2), Eabs(3), C1, C2, Wcc, and Wcr. The first 3 parameters fix the absorption energy for electrons, photons, and positrons, defining the cutoff energy below which simulation is discontinued (50 $\mathrm{eV}$ ) and the residual energy of the particle deposited locally. The remaining parameters control the mixed simulation algorithm for the transport of electrons and positrons. To force detailed (event-byevent) simulation, the latter parameters were set to zero (21).

The cell model consists of 2 homogeneous spheres of liquid water (mass density $\rho=1 \mathrm{gcm}^{-3}$ ), representing the cell and its nucleus, immersed in an infinite water medium (Fig. 1). Cell $\left(R_{\mathrm{C}}\right)$ and nucleus $\left(R_{\mathrm{N}}\right)$ radii combinations as tabulated by the MIRD Committee (14) were considered, and the list of $R_{\mathrm{C}}$ and $R_{\mathrm{N}}$ values was expanded to include larger cell geometries (up to $R_{\mathrm{C}}=12 \mu \mathrm{m}$ and $R_{\mathrm{N}}=11 \mu \mathrm{m}$ ) (19). Typically, $2 \times 10^{9}$ primary particles were simulated in each run.

\section{$S$ Value Calculations}

Monte Carlo transport of the complete radiation spectra based on the unabridged nuclear decay data (RADTABS software, version 2.2) (22) was used for all radionuclides except ${ }^{90} \mathrm{Nb}$ and ${ }^{117 \mathrm{~m}} \mathrm{Sn}$, for which

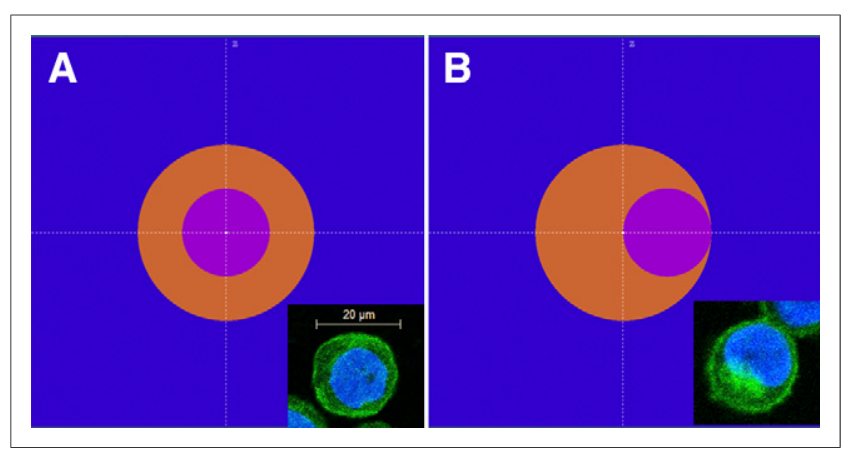

FIGURE 1. Spheric geometric models generated with PENELOPE (20): concentric (A) and eccentric (B) cells $\left(R_{\mathrm{C}}=10 \mu \mathrm{m}, R_{\mathrm{N}}=5 \mu \mathrm{m}\right)$. Inserts display cell and nucleus arrangement of MDA-MB-468 (A) and H2N (B) breast cancer cells. Cytoplasm and nucleus have been stained with green and blue fluorescent dye, respectively.

the condensed Auger electron + Coster-Kronig electron + internal conversion electron $(\mathrm{AE}+\mathrm{CK}+\mathrm{IE})$ spectrum was used because the unabridged spectrum was not provided in the tabulations. In the case of ${ }^{89} \mathrm{Zr},{ }^{90} \mathrm{Nb}$, and ${ }^{99 \mathrm{~m}} \mathrm{Tc}$, the full $\beta$ spectra were included. The $\mathrm{AE}+\mathrm{CK}+\mathrm{IE}$ and $\beta$ particle contributions to $S$ values were determined separately. Taking the nucleus as the target, simulations were run assuming uniformly distributed activity in the nucleus $(\mathrm{N} \leftarrow \mathrm{N})$, in the cytoplasm $(\mathrm{N} \leftarrow \mathrm{Cy})$, or on the cell surface $(\mathrm{N} \leftarrow \mathrm{CS})$. Cellular $S$ values are the mean absorbed dose to the target region (T) per unit cumulated activity in the source region $(\mathrm{S}) ; S(\mathrm{~T} \leftarrow \mathrm{S})$ according to the MIRD formalism is

$$
S(\mathrm{~T} \leftarrow \mathrm{S})=\frac{1}{m_{\mathrm{T}}} \sum_{j} y_{j} E_{j} \phi_{j}(\mathrm{~T} \leftarrow \mathrm{S}),
$$

where $y_{j}$ is the number of electrons (yield) emitted per transition $j$ with energy $E_{j}$, and $\phi_{j}(\mathrm{~T} \leftarrow \mathrm{S})$ is the fraction of the source energy deposited in the target region $\mathrm{T}$ (mass $m_{\mathrm{T}}$ ) from activity in the source region $\mathrm{S}$. $S$ values included in Supplemental Tables 2-13 were calculated from an event-by-event Monte Carlo simulation implementing Equation 1. The resulting $S$ values except for the nuclides ${ }^{89} \mathrm{Zr}$, ${ }^{90} \mathrm{Nb}$, and ${ }^{119} \mathrm{Sb}$, which were not included in the MIRD monograph, were compared with those in the MIRD tabulations (14) derived from Equation 2. The $S$ value in the continuous-slowing-down, straight-trajectory approximation is given by

$$
S(\mathrm{~T} \leftarrow \mathrm{S})=\frac{1}{m_{T}} \sum_{j} y_{j} E_{j} \int_{0}^{r_{\mathrm{CSDA}}\left(E_{j}\right)} \psi_{\mathrm{T} \leftarrow \mathrm{S}}(r) \frac{1}{E_{j}} S_{\mathrm{col}}\left(E_{j} ; r\right) \mathrm{d} r,
$$

where $\psi_{\mathrm{T} \leftarrow \mathrm{S}}(r)$ is the geometric reduction factor $(14), S_{\mathrm{col}}\left(E_{j} ; r\right)$ is a semiempiric electronic (collision) stopping power of an electron with initial energy $E_{j}$ after passing a distance $r$ through the medium, and $r_{\mathrm{CSDA}}$ is the range in the continuous-slowing-down approximation.

\section{DPKs}

For DPKs, a point isotropic radiation source was placed in an infinite liquid water medium and the mean absorbed dose from the emitted electrons (AE $+\mathrm{CK}+\mathrm{IEs}$ and $\beta$ particles) was scored in 1-nmthick spheric shells around the decay site. Mean absorbed doses were tallied up to a radial distance of $30 \mu \mathrm{m}$ from the point source. This corresponded to the radius of a sphere in which $100 \%$ of all emitted energy from the Auger electron and Coster-Kronig electron spectra 
was absorbed for ${ }^{67} \mathrm{Ga},{ }^{80 \mathrm{~m}} \mathrm{Br},{ }^{89} \mathrm{Zr},{ }^{90} \mathrm{Nb},{ }^{99 \mathrm{~m}} \mathrm{Tc},{ }^{111} \mathrm{In},{ }^{117 \mathrm{~m}} \mathrm{Sn},{ }^{119} \mathrm{Sb}$, ${ }^{123} \mathrm{I},{ }^{125} \mathrm{I}$, and $90 \%$ was absorbed for ${ }^{195 \mathrm{mPt}}$ and ${ }^{201} \mathrm{Tl}$.

To compare the dose deposition of the radionuclides with that of ${ }^{223} \mathrm{Ra}(22)$, the ratio of the DPKs calculated for spheres representing different DNA condensation states was determined. The energy deposited by the $5.77-\mathrm{MeV} \alpha$ particles was approximated by multiplying the mass electronic stopping power $\left(800 \mathrm{MeVcm}^{2} / \mathrm{g}\right)$ over the path length (i.e., the radius of the sphere), whereas energy deposition of the $\mathrm{AE}+\mathrm{CK}+\mathrm{IE}$ spectrum was determined by event-by-event simulation.

\section{RESULTS}

\section{Monte Carlo-Calculated S Values}

Cellular $S$ values calculated from Monte Carlo simulations are provided in Supplemental Tables 2-13. The statistical uncertainty of the $S$ values was less than $1.3 \%$ with $95 \%$ probability (type A uncertainty). The contribution of photons is much smaller than that of electrons ( $<2 \%$ of total $S$ values) and was disregarded in the present $S$ value tabulations; this was also done to facilitate comparison with MIRD $S$ values, for which the contribution from photon radiations was not included (Supplemental Fig. 1). For each radionuclide, the contributions to $S$ values of the Auger electrons and Coster-Kronig electrons, as well as, when appropriate, the $\beta$ spectra, is provided. In the case of ${ }^{99 \mathrm{~m}} \mathrm{Tc}$, the contribution of the $\beta$ spectra to the cellular $S$ values is negligible (on average $<0.003 \%$ to $S(\mathrm{~N} \leftarrow \mathrm{N})$, as expected from the $\beta^{-}$yield, and $<0.03 \%$ to $S(\mathrm{~N} \leftarrow \mathrm{Cy})$ and $S(\mathrm{~N} \leftarrow \mathrm{CS}))$, and therefore the contribution of $S$ ( $\beta$ spectra) to the total was omitted. $S$ values were verified using the simulated DPKs, with differences of $2 \%$ or less (data not shown).

In summary, the $S$ values calculated from PENELOPE Monte Carlo simulations were in excellent agreement with the MIRD data when the source and target regions strongly overlapped, that is, for $\mathrm{N} \leftarrow \mathrm{N}$ configurations. The differences between PENELOPE and MIRD for $S(\mathrm{~N} \leftarrow \mathrm{N})$ values were generally smaller than $10 \%$, with MIRD values consistently smaller than PENELOPE values. The differences tended to decrease with increasing $R_{\mathrm{N}}$; however, discrepancies increase when the source is far from the target region, as is the case for $\mathrm{N} \leftarrow \mathrm{Cy}(\leq 30 \%)$ and $\mathrm{N} \leftarrow \mathrm{CS}(\leq 60 \%)$. This increased discrepancy can be ascribed to the respective calculation approaches; that is, the MIRD method propagates electrons in straight trajectories, not taking energy straggling into account. PENELOPE as a rule overestimates the dose contributions for all 3 source-target configurations except for ${ }^{67} \mathrm{Ga},{ }^{99 \mathrm{~m}} \mathrm{Tc}$, and ${ }^{201} \mathrm{Tl}$, for which PENELOPE underestimates the $\mathrm{N} \leftarrow \mathrm{Cy}$ and $\mathrm{N} \leftarrow \mathrm{CS}$ contributions compared with MIRD $S$ values.

\section{Effect of Cellular Geometry on S Values}

The effect of cellular geometry on the $S$ values, taking into account only contributions from the $\mathrm{AE}+\mathrm{CK}+\mathrm{IE}$ spectrum, is summarized in Supplemental Tables 2-13. The self-dose to the nucleus is obviously not influenced by the position of the nucleus relative to the cell (concentric vs. eccentric nucleus arrangements) or the shape of the cell. However, the position of the nucleus, especially for eccentric arrangements, can contribute significantly to crossfire of neighboring cells, and this would specifically be seen for radionuclides with longer-range Auger electrons and internal conversion electrons. Generally, the contribution to $S(\mathrm{~N} \leftarrow \mathrm{Cy})$ is less for eccentric than concentric cell arrangements, with the greatest differences $(\leq 30 \%)$ noted in smaller $R_{\mathrm{C}} / R_{\mathrm{N}}$ configurations. These differences become less pronounced $(<10 \%)$ when $R_{\mathrm{C}}$ and $R_{\mathrm{N}}$ increase. For eccentric versus concentric nuclear arrangements in which the activity is uniformly distributed on the cell surface, the greatest contribution to the mean absorbed dose delivered to the nucleus is again seen for small $R_{\mathrm{N}}$ relative to $R_{\mathrm{C}}$ (Supplemental Fig. 2, $R_{\mathrm{C}}=5 \mu \mathrm{m}$ and $R_{\mathrm{N}}=2 \mu \mathrm{m}$ ). It follows that $S(\mathrm{~N} \leftarrow \mathrm{CS})$ contributions in eccentric nucleus configurations increase as the size of the nucleus decreases and thus the distance of the nucleus from the cell surface decreases in relation to the range of the particles. This is particularly apparent for ${ }^{89} \mathrm{Zr}$ (Supplemental Fig. 4), for which up to a 60 -fold increase in nuclear dose is observed for $R_{\mathrm{C}}=10 \mu \mathrm{m}$ and $R_{\mathrm{N}}=5 \mu \mathrm{m}$. However, this effect decreases when the contribution from the $\beta$ spectra is included (Fig. 2A).

To assess the effect of the nucleus position (in relation to the cell surface) on $S(\mathrm{~N} \leftarrow \mathrm{Cy})$ and $S(\mathrm{~N} \leftarrow \mathrm{CS})$, the eccentricity was evaluated for a cell with dimensions $R_{\mathrm{C}}=10 \mu \mathrm{m}$ and $R_{\mathrm{N}}=5 \mu \mathrm{m}$ (Fig. 2 ). Eccentricity is expressed as the ratio of $S$ values for eccentric compared with concentric cell-nucleus arrangements. The nucleus position is shifted by $0.5-\mu \mathrm{m}$ increments from the center until it is contiguous with the cell surface. In the case of ${ }^{89} \mathrm{Zr}$ and ${ }^{90} \mathrm{Nb}$, the contribution of the $\beta$ spectra is included. Nucleus eccentricity had the least effect on ${ }^{80 \mathrm{~m}} \mathrm{Br},{ }^{117 \mathrm{~m}} \mathrm{Sn},{ }^{123} \mathrm{I}$, and ${ }^{125} \mathrm{I}$, with the contribution from cytoplasmic mean absorbed dose $S(\mathrm{~N} \leftarrow \mathrm{Cy})$ decreasing by less than $25 \%$ and the contribution from cell surface mean absorbed dose $S(\mathrm{~N} \leftarrow \mathrm{CS})$ increasing by less than $30 \%$. For ${ }^{89} \mathrm{Zr}$, the $\beta$ spectra contributes approximately $25 \%$ to the overall mean absorbed dose for $S(\mathrm{~N} \leftarrow \mathrm{Cy})$ configurations, whereas this contribution decreases from approximately $95 \%$ to $30 \%$ for $S(\mathrm{~N} \leftarrow \mathrm{CS})$ configurations as the nucleus shifts toward the cell surface. Conversely, the ${ }^{90} \mathrm{Nb} \beta$ spectra contribution to $S(\mathrm{~N} \leftarrow \mathrm{Cy})$ and $S(\mathrm{~N} \leftarrow \mathrm{CS})$ configurations varied by approximately $30 \%$ and $30 \%-45 \%$, respectively. The effect of eccentricity on dose calculations is discussed in Supplemental Figure 3.

\section{Contribution of Auger Electron to $S$ Values}

Self-dose to the nucleus for most of the radionuclides studied is almost exclusively due to Auger electrons, with internal conversion electrons (and, when appropriate, $\beta$ particles) responsible for the remaining mean absorbed doses (Supplemental Tables 2-13). Cytoplasmically distributed Auger electrons contribute less when $R_{\mathrm{C}}$ increases than when $R_{\mathrm{N}}$ increases. The contribution of Auger electrons to $S(\mathrm{~N} \leftarrow \mathrm{CS})$ can be roughly divided into 3 categories: the contribution increases when the distance between $R_{\mathrm{C}}$ and $R_{\mathrm{N}}$

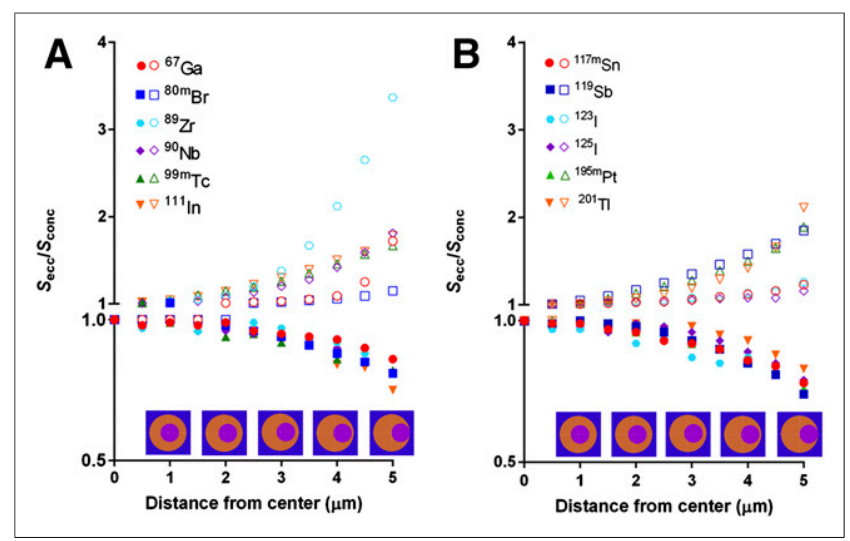

FIGURE 2. (A and B) Effect of eccentricity on $S$ values: ratio of eccentric and concentric $S$ values for single cell $\left(R_{\mathrm{C}}=10 \mu \mathrm{m}, R_{\mathrm{N}}=5 \mu \mathrm{m}\right)$ as function of nucleus distance from center of cell. Solid and open symbols denote $S$ value ratios for $\mathrm{N} \leftarrow \mathrm{Cy}$ and $\mathrm{N} \leftarrow \mathrm{CS}$, respectively. 
decreases $\left({ }^{67} \mathrm{Ga},{ }^{80 \mathrm{~m}} \mathrm{Br},{ }^{99 \mathrm{~m}} \mathrm{Tc},{ }^{195 \mathrm{~m} P t}\right.$, and $\left.{ }^{201} \mathrm{Tl}\right)$; the contribution increases when the distance between $R_{\mathrm{C}}$ and $R_{\mathrm{N}}$ increases $\left({ }^{89} \mathrm{Zr}\right.$, ${ }^{90} \mathrm{Nb}$, and ${ }^{119} \mathrm{Sb}$ ); and the contribution of surface-bound Auger electrons to the nucleus is influenced by the end of the range of some electrons in the spectra $\left({ }^{111} \mathrm{In},{ }^{117 \mathrm{~m}} \mathrm{Sn},{ }^{123} \mathrm{I}\right.$, and $\left.{ }^{125} \mathrm{I}\right)$. In the last category, ${ }^{111} \mathrm{In},{ }^{123} \mathrm{I}$, and ${ }^{125} \mathrm{I}$ are largely unaffected by $R_{\mathrm{C}}$ and $R_{\mathrm{N}}$ combinations, which makes these radionuclides more attractive for targeting strategies not relying on internalization of the construct.

\section{DPKs}

The DPKs for the radionuclides studied are presented in Figure 3. The DPKs calculated for ${ }^{89} \mathrm{Zr}$ and ${ }^{90} \mathrm{Nb}$ include the contributions of their $\beta$ spectra (Supplemental Fig. 4). For all radionuclides considered, the energy deposition in the first 1-nm shell ranged from a minimum of $0.14 \mathrm{keV}\left({ }^{67} \mathrm{Ga}\right)$ to a maximum of $1.21 \mathrm{keV}$

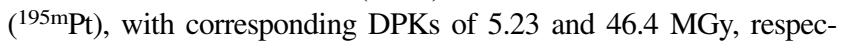
tively. If a DNA targeting strategy is adopted, the radionuclides that will result in the highest DPK over a radial distance of $11 \mathrm{~nm}$, chosen to represent chromatin structure (i.e., DNA double-helix wrapped around histones) are, in decreasing order of efficacy, ${ }^{195 \mathrm{~m}} \mathrm{Pt},{ }^{201} \mathrm{Tl}$, ${ }^{125} \mathrm{I},{ }^{119} \mathrm{Sb},{ }^{111} \mathrm{In},{ }^{123} \mathrm{I},{ }^{117 \mathrm{~m}} \mathrm{Sn},{ }^{80 \mathrm{~m}} \mathrm{Br},{ }^{90} \mathrm{Nb},{ }^{89} \mathrm{Zr}$, ${ }^{99 \mathrm{~m} \mathrm{Tc}}$, and ${ }^{67} \mathrm{Ga}$. DPKs decrease dramatically by 8-9 orders of magnitude over the $30-\mu \mathrm{m}$ distance considered, falling to mean absorbed doses of a few milligrays.

\section{Relative Dose of Auger Electrons Compared with a Particles}

A comparison of the energy deposition from $\alpha\left({ }^{223} \mathrm{Ra}\right)$ and Auger electron emitters ( $\mathrm{AE}+\mathrm{CK}+\mathrm{IE}$ and $\beta$ particles) in spheres of diameters representing different DNA condensation states is shown in Figure 4. The energy deposition in a sphere $2 \mathrm{~nm}$ in diameter, representing the DNA double-helix, exceeds that of a monoenergetic

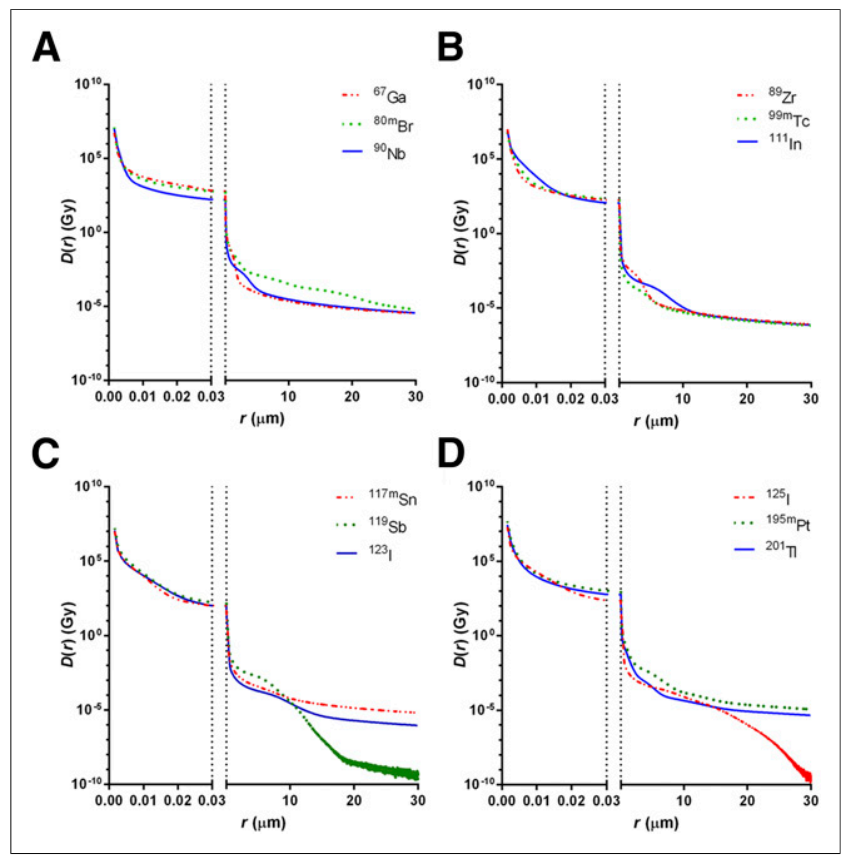

FIGURE 3. DPKs (Gy) calculated in 1-nm shells up to $30 \mu \mathrm{m}$ from

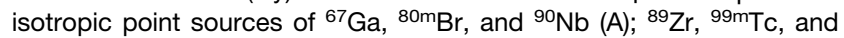
${ }^{111} \mathrm{In}(\mathrm{B}) ;{ }^{117 \mathrm{~m} S n},{ }^{119} \mathrm{Sb}$, and ${ }^{123}$ (C); and ${ }^{125}$, ${ }^{195 \mathrm{mPt}}$, and ${ }^{201} \mathrm{TI}(\mathrm{D})$. DPKs show energy deposition for complete particulate spectra $(A E+C K+I E$ and $\beta$ particles).
5.77-MeV $\alpha$ particle for all the radionuclides apart from ${ }^{99 \mathrm{~m}} \mathrm{Tc}$ and ${ }^{67} \mathrm{Ga}$ (Fig. 4A). When the Auger electron emitters are compared with the complete particulate spectrum of ${ }^{223} \mathrm{Ra}$ (5.77-MeV $\alpha$, $\mathrm{AE}+\mathrm{CK}+\mathrm{IE}$, and daughters), the effect is vastly reduced, with only 195mPt depositing a comparable amount of energy (Fig. 4B). In general, the relative dose of the Auger electron-emitting radionuclides diminishes dramatically as diameters representing DNA condensation states increase.

\section{DISCUSSION}

To evaluate the virtues of Auger electron-emitting radionuclides that have previously been suggested for therapeutic or imaging purposes, a single-cell dosimetric approach was undertaken by considering all energy deposition events and related probabilities. First, cellular $S$ values were determined by Monte Carlo transport of all particulate radiation following the MIRD formalism, and second, DPKs were calculated for all the radionuclides considered in 1-nm radial bins up to $30 \mu \mathrm{m}$. In this regard, it is crucial to use a Monte Carlo code that provides an event-by-event simulation, as a loss of spatial resolution during particle transport from condensed simulation algorithms (i.e., grouping elastic, inelastic, and radiative events), and underestimation of secondary electrons, have a large effect on energy deposition (23). PENELOPE can perform event-by-event coupled photon-electron transport simulations, thus providing a more accurate estimation of the energy deposition than is possible with other general-purpose Monte Carlo codes $(24,25)$.

PENELOPE cellular $S$ values for overlapping source and target agree well with MIRD and previously published $S$ values (26), with differences of less than $10 \%$ and $5 \%$, respectively. However, larger discrepancies are seen when the source and target volumes are farther apart. The greatest difference $(\leq 60 \%)$ between PENELOPE and MIRD $S$ values was when activity was assumed to be distributed on the cell surface in accordance with the observations of Uusijärvi et al. (25). These differences can be ascribed to the fact that MIRD $S$ values are based on approximate DPKs calculated from the collision stopping power (i.e., assuming straight electron trajectories and neglecting energy straggling). Differences might also be attributed to the different energy spectra used. Whereas the unabridged radiation spectrum from the MIRD monograph (22) was adopted in the Monte Carlo simulations, MIRD $S$ values were generated from the energy spectra provided by Eckerman et al. (27). A limitation of the PENELOPE code when Auger electrons are transported is the set cutoff energy of $50 \mathrm{eV}$. Many of the radionuclides evaluated here have an abundance of low-energy Auger electrons, less than $50 \mathrm{eV}$, which thus are not transported. This could potentially lead to an overestimation of energy deposited within the first few nanometers of the DPKs calculated.

It was recently demonstrated that a small variation in mean absorbed dose can have a significant impact on tumor control probability (28). It is therefore crucial that the selection of a radionuclide-delivery vehicle addresses not only the distribution (particularly internalization) of the radionuclide but also the geometry of the targeted cells. As is shown, eccentric cell-nucleus arrangements can lead to increased $S$ values for some of the radionuclides studied here. The greatest effect of nucleus eccentricity was noted for $\mathrm{S}(\mathrm{N} \leftarrow \mathrm{CS})$ configurations. For example, the dose to the nucleus from cell surface source arrangements for ${ }^{201} \mathrm{Tl}$ increased by more than $200 \%$. As is the case with the other radionuclides $\left({ }^{67} \mathrm{Ga},{ }^{89} \mathrm{Zr}\right.$, ${ }^{90} \mathrm{Nb}$, 


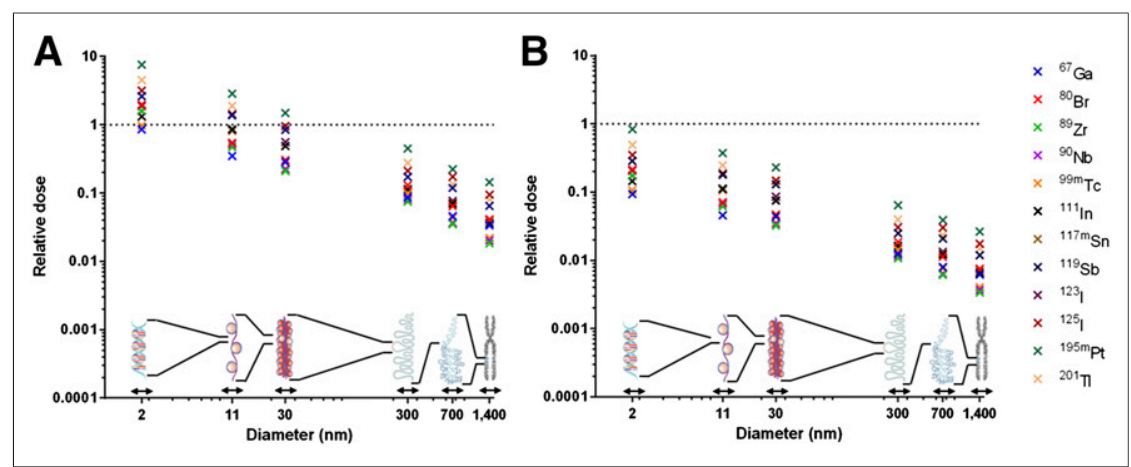

FIGURE 4. Relative dose, comparing energy deposition of monoenergetic 5.77-MeV a particle (A) and ${ }^{223} \mathrm{Ra}(\mathrm{a}, \mathrm{AE}+\mathrm{CK}+\mathrm{IE}$, and daughters) (B) with Auger electron-emitting radionuclides. Relative dose is given as ratio of energy deposited in spheres, with diameters representing different DNA condensation states (i.e., DNA double-helix [2 nm], DNA wrapped around histones [chromatin, $11 \mathrm{~nm}$ ], chromatin fiber of packed nucleosomes [30 nm], chromosome section in extended form $[300 \mathrm{~nm}]$, condensed section of chromosome [700 nm], and entire mitotic chromosome $[1,400 \mathrm{~nm}])$.

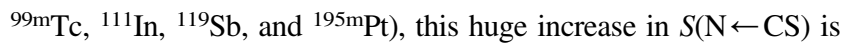
due to an abundance of very low-energy electrons in their spectra. This property could be advantageous for cell types with eccentric nucleus arrangements for which targeting is achieved via surface-bound receptors, but it could also have a deleterious effect on surrounding normal cells in close contact with the targeted cell. Another point of consideration with eccentric cell-nucleus arrangements is cell size; for smaller cells and nuclei the effect of eccentricity is rather marked, with up to a 2-fold difference in dose.

The spatial dose gradients in the respective DPK spectra are the result of the ends of ranges of major low-energy electron groups. The sharp drop in dose after the first few nanometers illustrates the highly localized energy deposition caused by the Auger electrons, with local mean absorbed doses over this range in excess of $10 \mathrm{MGy}$. Radial dose distributions diverge by less than $25 \%$ compared with those previously reported for ${ }^{111}$ In and ${ }^{125} \mathrm{I}(29,30)$ and might be ascribed to the different radiation spectra used.

Although $\beta$ emitters are clinically widely used because of their long range, the recent success of the $\alpha$-emitting radionuclide ${ }^{223} \mathrm{Ra}(31)$ has focused attention on the use of shorterrange radionuclides for molecularly targeted radiotherapy. From the viewpoint of their cell-killing potential, the advantage of Auger electron-emitting radionuclides is their extremely short range and localized dose deposition. New strategies are being developed for delivery of Auger electron-emitting radionuclides to the nucleus, such as carbon nanotubes (33), gold nanoparticles (34), antibody-based peptides (35), and cell-penetrating peptides (36). Intranuclear delivery of Auger electron-emitting constructs results in relative biological effectiveness similar to that of $\alpha$ emitters but with a reduced crossfire effect compared with $\alpha$ emitters, making them more suitable for single-cell irradiation (9). The DPKs of ${ }^{223} \mathrm{Ra}$ and the Auger electron emitters show that with respect to the energy deposited in spheres of DNA dimensions, only the higher-mass-number Auger electron emitters deposit comparable amounts of energy. However, comparison with a monoenergetic 5.77- $\mathrm{MeV} \alpha$ particle notes the major advantage of Auger electron emitters at distances less than $11 \mathrm{~nm}$, which is in agreement with data presented by Charlton (36).

\section{CONCLUSION}

Many Auger electron-emitters are suitable for theranostic applications, enabling simultaneous detection (PET and SPECT imaging) and treatment. The data presented here suggest that single-cell characteristics should be considered when one is designing these molecularly targeted agents. The challenge will be to match the delivery strategy with the physical properties of a particular radionuclide.

\section{DISCLOSURE}

The costs of publication of this article were defrayed in part by the payment of page charges. Therefore, and solely to indicate this fact, this article is hereby marked "advertisement" in accordance with 18 USC section 1734. This research was supported by Cancer Research U.K. (CR-UK), the Medical Research Council (MRC), the CR-UK Oxford Centre, and the Generalitat de Catalunya (project 2014 SGR 846). No other potential conflict of interest relevant to this article was reported.

\section{REFERENCES}

1. Pool SE, Krenning EP, Koning GA, et al. Preclinical and clinical studies of peptide receptor radionuclide therapy. Semin Nucl Med. 2010;40:209-218.

2. Rebischung C, Hoffmann D, Stefani L, et al. First human treatment of resistant neoplastic meningitis by intrathecal administration of MTX plus ${ }^{125} \mathrm{IUdR}$. Int J Radiat Biol. 2008;84:1123-1129.

3. Vallis KA, Reilly RM, Scollard D, et al. Phase I trial to evaluate the tumor and normal tissue uptake, radiation dosimetry and safety of ${ }^{111}$ In-DTPA-human epidermal growth factor in patients with metastatic EGFR-positive breast cancer. Am J Nucl Med Mol Imaging. 2014;4:181-192.

4. Kassis AI, Adelstein SJ. Radiobiologic principles in radionuclide therapy. $\mathrm{J} \mathrm{Nucl}$ Med. 2005;46(suppl):4S-12S.

5. Hamoudeh M, Kamleh MA, Diab R, Fessi H. Radionuclides delivery systems for nuclear imaging and radiotherapy of cancer. Adv Drug Deliv Rev. 2008;60:1329-1346.

6. Kelkar SS, Reineke TM. Theragnostics: combining imaging and therapy. Bioconjug Chem. 2011;22:1879-1903.

7. Govindan SV, Goldenberg D, Elsamra S, et al. Radionuclides linked to a CD74 antibody as therapeutic agents for B-cell lymphoma: comparison of Auger electron-emitters with $\beta$-particle emitters. J Nucl Med. 2000;41:2089-2097.

8. Bernhardt P, Forssell-Aronsson E, Jacobsson L, Skamemark G. Low-energy electron-emitters for targeted radiotherapy of small tumours. Acta Oncol. 2001;40: 602-608.

9. Howell RW, Narra VR, Rao DV, Sastry KSR. Radiobiological effects of intracellular ${ }^{210}$ Po alpha emissions: a comparison with Auger-emitters. Radiat Prot Dosimetry. 1990;31:325-328.

10. Britz-Cunningham SH, Adelstein SJ. Molecular targeting with radionuclides: state of the science. J Nucl Med. 2003;44:1945-1961.

11. Cornelissen B, Vallis KA. Targeting the nucleus: an overview of Auger-electron radionuclide therapy. Curr Drug Discov Technol. 2010;7:263-279.

12. Pouget J-P, Santoro L, Raymond L, et al. Cell membrane is a more sensitive target than cytoplasm to dense ionization produced by Auger electrons. Radiat Res. 2008;170:192-200.

13. Howell RW, Rao DV, Hou DY, Narra VR, Sastry KSR. The question of relative biological effectiveness and quality factor for Auger-emitters incorporated into proliferating mammalian cells. Radiat Res. 1991;128:282-292.

14. Goddu S, Howell R, Bouchet L, Bolch W, Rao D. MIRD Cellular S Values. Reston, VA: Society of Nuclear Medicine and Molecular Imaging; 1997.

15. Nettleton JS, Lawson RS. Cellular dosimetry of diagnostic radionuclides for spherical and ellipsoidal geometry. Phys Med Biol. 1996;41:1845-1854.

16. Sastry KSR, Haydock C, Basha AM, Rao DV. Electron dosimetry for radioimmunotherapy: optimal electron energy. Radiat Prot Dosimetry. 1985;13:249-252. 
17. Sjöholm H, Ljunggren KL, Adell R, Brun A, Ceberg C, Strand S-E. Necrosis of malignant gliomas after intratumoral injection of ${ }^{201} \mathrm{Tl}$ in vivo in the rat. Anticancer Drugs. 1995;6:109-114.

18. Srivastava SC. Paving the way to personalized medicine: production of some promising theragnostic radionuclides at Brookhaven National Laboratory. Semin Nucl Med. 2012;42:151-163.

19. Vaziri B, Wu H, Dhawan AP, Du P, Howell RW. MIRD pamphlet no. 25: MIRDcell V2.0 software tool for dosimetric analysis of biologic response of multicellular populations. J Nucl Med. 2014;55:1557-1564.

20. Salvat F, Fernández-Varea JM, Sempau J, eds. PENELOPE-2011: a code system for Monte Carlo simulation of electron and photon transport. OECD Nuclear Energy Agency website. https://www.oecd-nea.org/science/docs/2011/nsc-doc2011-5.pdf. Published 2011. Accessed July 23, 2015.

21. Fernández-Varea JM, González-Muñoz G, Galassi ME, et al. Limitations (and merits) of PENELOPE as a track-structure code. Int J Radiat Biol. 2012;88:66-70.

22. Eckerman KF, Endo A, eds. MIRD Radionuclide Data and Decay Schemes. Reston, VA: Society of Nuclear Medicine and Molecular Imaging; 2008.

23. Bernal MA, Liendo JA. An investigation on the capabilities of the PENELOPE MC code in nanodosimetry. Med Phys. 2009;36:620-625.

24. Botta F, Mairani A, Battistoni G, et al. Calculation of electron and isotopes dose point kernels with FLUKA Monte Carlo code for dosimetry in nuclear medicine therapy. Med Phys. 2011;38:3944-3954.

25. Uusijärvi H, Chouin N, Bernhardt P, Ferrer L, Bardiès M, Forssell-Aronsson E. Comparison of electron dose-point kernels in water generated by the Monte Carlo codes, PENELOPE, GEANT4, MCNPX, and ETRAN. Cancer Biother Radiopharm. 2009;24:461-467.

26. Faraggi M, Gardin I, Stievenart J-L, Bok B, Le Guludec D. Comparison of cellular and conventional dosimetry in assessing self-dose and cross-dose de- livered to the cell nucleus by electron emissions of ${ }^{99 \mathrm{~m}} \mathrm{Tc},{ }^{123} \mathrm{I},{ }^{111} \mathrm{In},{ }^{67} \mathrm{Ga}$ and ${ }^{201}$ Tl. Eur J Nucl Med. 1998;25:205-214.

27. Eckerman KF, Westfall RJ, Ryman JC, Cristy M. Nuclear Decay Data Files of the Dosimetry Research Group. Oak Ridge, TN: Oak Ridge National Laboratory; 1993. ORNL/TM-12350.

28. Begg AC, Stewart F, Vens C. Strategies to improve radiotherapy with targeted drugs. Nat Rev Cancer. 2011;11:239-253.

29. Sastry KSR. Biological effects of the Auger-emitter iodine-125: a review. Report No. 1 of AAPM Nuclear Medicine Task Group No. 6. Med Phys. 1992;19:13611370.

30. Rao DV, Sastry KSR, Grimmond HE, et al. Cytotoxicity of some indium radiopharmaceuticals in mouse testes. J Nucl Med. 1988;29:375-384.

31. Parker C, Pascoe S, Chodacki A, et al. A randomized, double-blind, dose-finding, multicenter, phase 2 study of radium chloride (Ra223) in patients with bone metastases and castration-resistant prostate cancer. Eur Urol. 2013;63:189-197.

32. Lacerda L, Russier J, Pastorin G, et al. Translocation mechanisms of chemically functionalised carbon nanotubes across plasma membranes. Biomaterials. 2012;33: 3334-3343.

33. Tkachenko AG, Xie H, Coleman D, et al. Multifunctional gold nanoparticlepeptide complexes for nuclear targeting. J Am Chem Soc. 2003;125:4700-4701.

34. Cornelissen B, Darbar S, Kersemans V, et al. Amplification of DNA damage by a $\gamma$ H2AX-targeted radiopharmaceutical. Nucl Med Biol. 2012;39:1142-1151.

35. Costantini DL, Chan C, Cai Z, Vallis KA, Reilly RM. ${ }^{111}$ In-labeled trastuzumab (Herceptin) modified with nuclear localization sequences (NLS): an Auger electron-emitting radiotherapeutic agent for HER2/neu-amplified breast cancer. $J$ Nucl Med. 2007;48:1357-1368.

36. Charlton DE. The range of high LET effects from ${ }^{125} \mathrm{I}$ decays. Radiat Res. 1986;107:163-171. 